\title{
I) norden
}

International Cooperative Initiatives

- from concept to impact

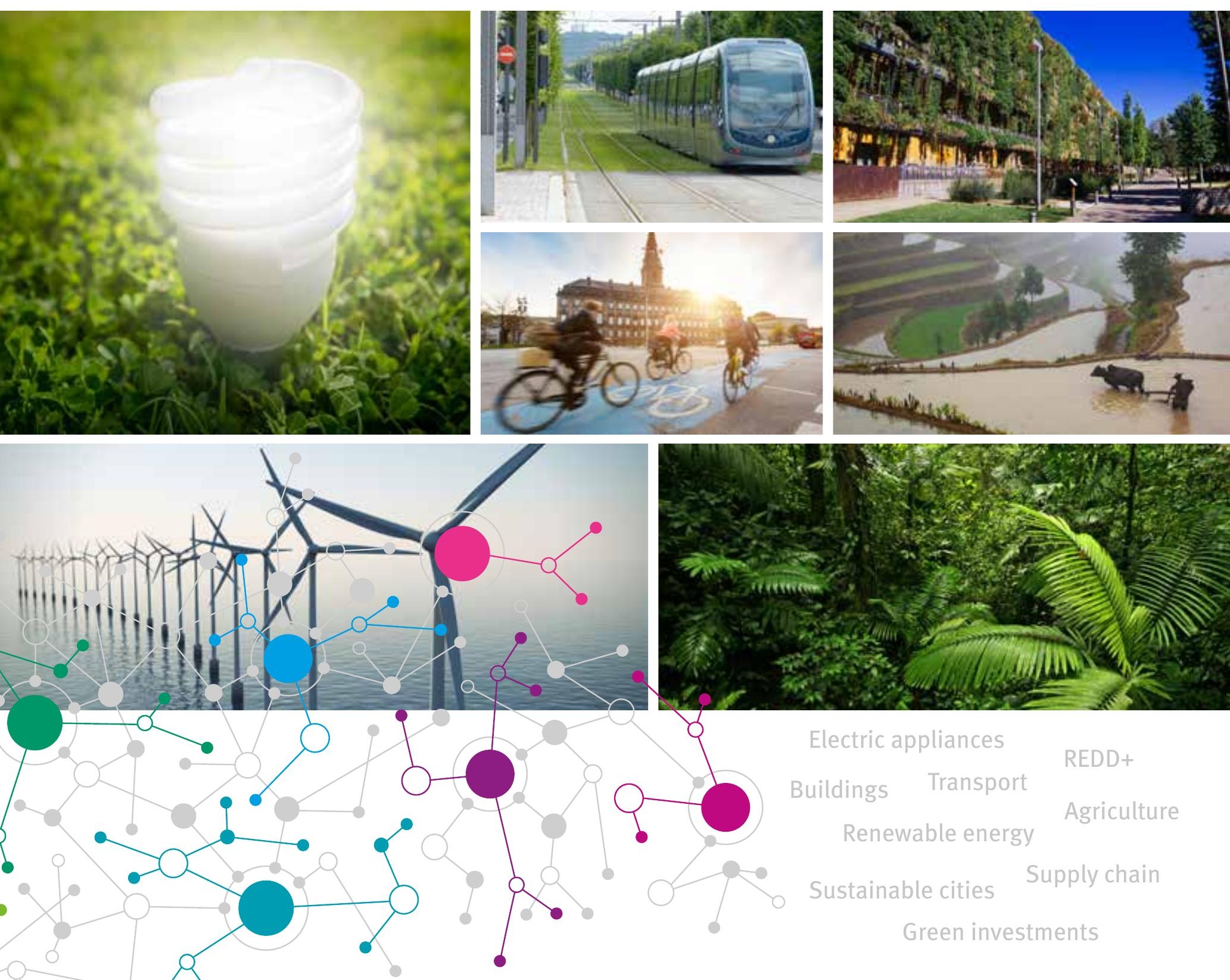


International Cooperative Initiatives

- from concept to impact

Ann Gardiner (Ecofys), Michelle Bosquet (Ecofys), David Webb (CISL) and Nicolette Bartlett (CISL)

ISBN 978-92-893-4517-0 (PRINT)

ISBN 978-92-893-4518-7 (PDF)

http://dx.doi.org/10.6027/ANP2016-716

ANP 2016:716

(C) Nordic Council of Ministers 2016

Layout: Gitte Wejnold

Cover photo: Norden.org

Photos: Norden.org

Typeface: Meta LF

This publication has been published with financial support by the Nordic Council of Ministers and the Netherlands Ministry of Infrastructure and the Environment. However, the contents of this publication do not necessarily reflect the views, policies or recommendations of the Nordic Council of Ministers nor the Dutch government.

www.norden.org/nordpub

\section{Nordic co-operation}

Nordic co-operation is one of the world's most extensive forms of regional collaboration, involving Denmark, Finland, Iceland, Norway, Sweden, and the Faroe Islands, Greenland, and Åland.

Nordic co-operation has firm traditions in politics, the economy, and culture. It plays an important role in European and international collaboration, and aims at creating a strong Nordic community in a strong Europe.

Nordic co-operation seeks to safeguard Nordic and regional interests and principles in the global community. Common Nordic values help the region solidify its position as one of the world's most innovative and competitive.

\author{
Nordic Council of Ministers \\ Ved Stranden 18 \\ DK-1061 Copenhagen $\mathrm{K}$ \\ Phone (+45) 33960200 \\ www.norden.org
}




\section{International Cooperative Initiatives \\ - from concept to impact}

Authors

Ann Gardiner (Ecofys), Michelle Bosquet (Ecofys), David Webb (CISL)

and Nicolette Bartlett (CISL) 



\section{Contents}

$\begin{array}{ll}\text { Foreword } & 6\end{array}$

$\begin{array}{lr}\text { 1. Developments in non-state climate action } & 8\end{array}$

2. The Climate Initiative Platform and the LPAA 12

3. Findings and outlook from the Update for Paris 16

4. Transfer of the platform to UNEP - Overall vision 18

Annex 1 - Putting the vision into operation $\quad 22$

Annex 2 - Expert Advisory Group $\quad 26$

Annex 3 - Transfer of the platform to UNEP and maintenance 27

Annex 4 - Data for assessment $\quad 28$ 


\section{Foreword}

The Paris Agreement is widely considered to be of historic significance sending a strong signal to non-state actors that countries stand behind curbing greenhouse gas emissions with the objective to keep temperature rise well below $2^{\circ} \mathrm{C}$, with efforts to stay below $1.5^{\circ} \mathrm{C}$. Still the Intended Nationally Determined Contributions submitted to the United Nations Framework Convention on Climate Change (UNFCCC) by national governments as of 7th of December 2015 will likely limit temperature rise to under $3^{\circ} \mathrm{C}$ but be insufficient to limit it to $2^{\circ} \mathrm{C}$ or lower. The multitude of international cooperative initiatives underway outside the formal negotiating process will be needed to support these government actions. Actors in these multi-stakeholder partnerships include regional and local governments, companies, financial institutions, NGOs and individuals. There is recognition that these cooperative initiatives can raise the level of ambition on climate change and there is significant focus on them through the Lima Paris Action Agenda (LPAA). Some initiatives are show-cased through the UNFCCC's Non-State Actor Zone for Climate Action (NAZCA) portal.
The Paris agreement welcomes the efforts by non-Party stakeholders and invites them to scale up their efforts and demonstrate these via the NAZCA portal. In response to the growing interest in the potential for international cooperative initiatives to take action on climate change, a platform initially containing information on 184 such initiatives was developed by an Ecofys-led project team supported by the Nordic Council of Ministers. It was published in beta version online on the platform: www.climateinitiativesplatform.org in December 2014. In the fall of 2015, with support by the Nordic Council of Ministers and the Netherlands Ministry of Infrastructure and the Environment, the platform was further updated and extended to take into account new initiatives and new sources of information. It now contains 241 initiatives in total and has been prepared for transfer in management to the United Nations Environment Programme (UNEP) for the beginning of 2016. This report highlights the information currently present in the Climate Initiative Platform as well as the changes and outlook for this comprehensive data on cooperative initiatives

post-2015. 


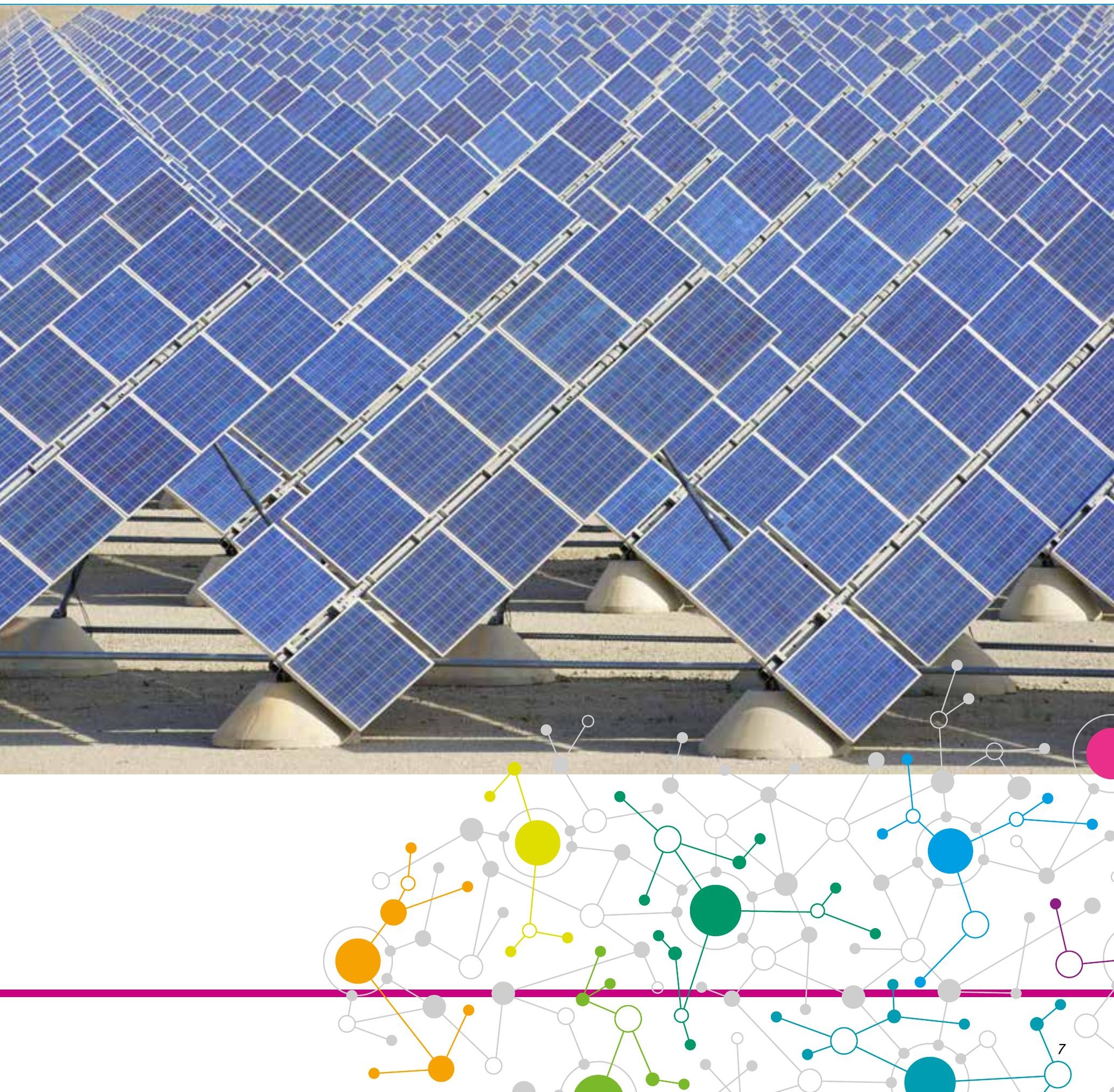




\section{Developments in non-state climate action}

Initiatives involving non-state actors such as businesses, cities and NGOs which catalyse climate action are now recognised as playing an important role in mitigating greenhouse gas emissions (GHG) and bridging the global emissions gap. In the run up to COP21 in Paris 2015, there has been significant focus on them through the Lima-Paris Action Agenda (LPAA), a joint undertaking of the Peruvian and French COP presidencies that aims to accelerate actions both pre-2020 and beyond. Additionally, a growing body of studies quantifying their effect and identifying success factors (CISL and Ecofys, 2015; Ecofys and CISL, 2014; PBL 2015; UNEP 2015; Yale 2015) have been published throughout the year. Since its official launch during a COP20 event in December 2014 in Lima, the Climate Initiative Platform (CIP) on international cooperative initiatives has provided the basis of much of the analysis and remains the only source of comprehensive information on cooperative initiatives.

The CIP platform was launched to provide open source data on international cooperative initiatives which meet the following criteria:

- $\quad$ Contribute to reducing greenhouse gas emissions;

- Are international in scope or have the potential for significant impact at global scale.

- Involve more than 2 parties taking voluntary action, either in the form of dialogues, formal multilateral processes or implementation initiatives.
To prepare the platform for Paris, Ecofys and University of Cambridge Institute of Sustainability Leadership (CISL) performed an update of the platform that includes a review of data on existing initiatives. In a second step the team investigated initiatives that would be suitable for inclusion in the Lima-Paris Action Agenda and the UNFCCC's Non-State Actor Zone for Climate Action (NAZCA). Both platforms are also dedicated to showcasing innovative and transformative initiatives and commitments from non-state actors for Paris and beyond.

Following these activities, the Climate Initiative Platform has been transferred to the United Nations Environment Programme (UNEP) early in 2016. Management through UNEP will allow the database to achieve a higher profile and will help ensure the information on the platform is kept up to date.

This report describes the updated platform, draws conclusions from the interactions with the initiatives during that updating and gives a vision for the future of the platform.

\section{Climate Initiative Platform update}

Over the last year, there has been significant activity in the area of international cooperative initiatives. While eight initiatives are no longer active, or do not match the CIP criteria anymore due to changes, many more initiatives were started or strengthened over the past 12 months. A number of strong and forward thinking lead organisations have increased the number of 
initiatives they have been facilitating, or have created over-arching programmes. Examples include the World Business Council for Sustainable Development (WBCSD) that hosts nine working groups under its Low Carbon Technology Partnerships Initiative (LCTPi). As of 30th November, 2015, 57 new initiatives have been included in the Climate Initiative Platform since Lima. Initiatives launched during or after COP21 have not been included in the update.

These initiatives cover a broad range of sectors as is shown in Figure 1. The largest number of initiatives focus on the themes Energy Efficiency, Transport and Renewable Energy and the largest growth in 2015 was in Efficiency, Transport and Industry. The theme Energy Supply did not show any new initiatives, while growth in Renewable Energy was relatively modest.
A detailed analysis into the reasons behind the observed developments was not carried out as part of this project.

Looking at the type of lead organisation and their locations it is evident that the trends visible in cooperative initiatives at the end of 2014 remain after the update. The largest development can be seen in the doubling of international organisations taking the lead in convening and organising initiatives. Partnerships, between different organisations continue to form strong lead organisations. The number of lead organisations formed by business have doubled over the past year. Lead organisations of cooperative initiatives are still generally located in Europe and North America, although this does not mean that action is only taking place in these regions.

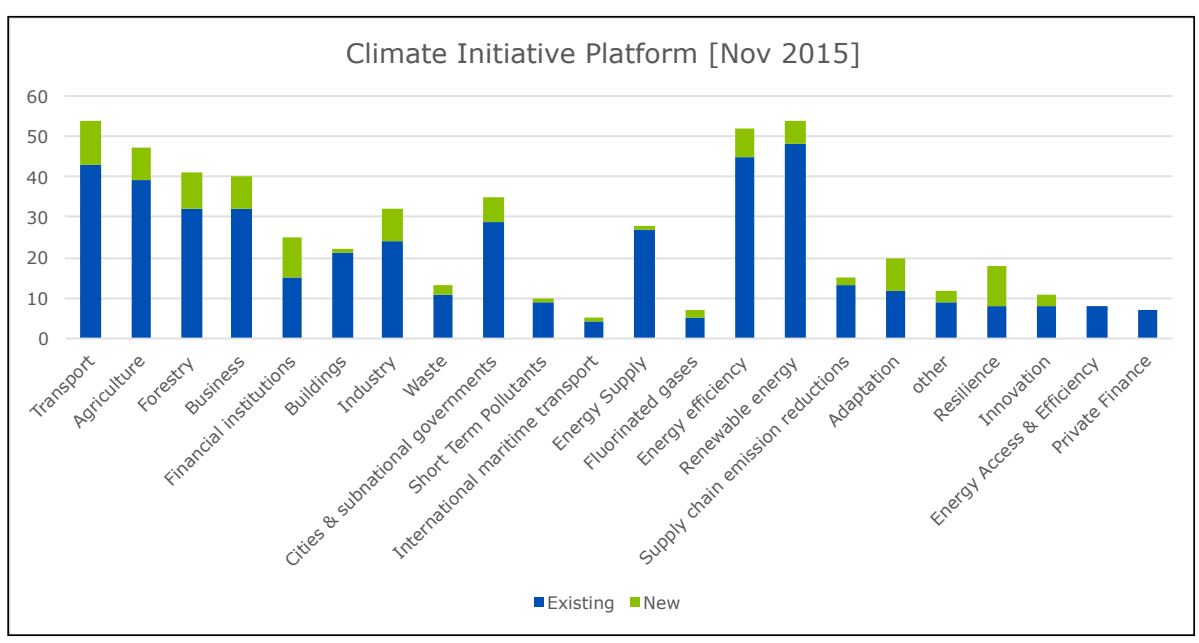

Figure 1

Overview of the different themes and sectors covered by the Climate Initiative Platform. ${ }^{1}$ Initiatives uploaded during 2015 are marked in green. 

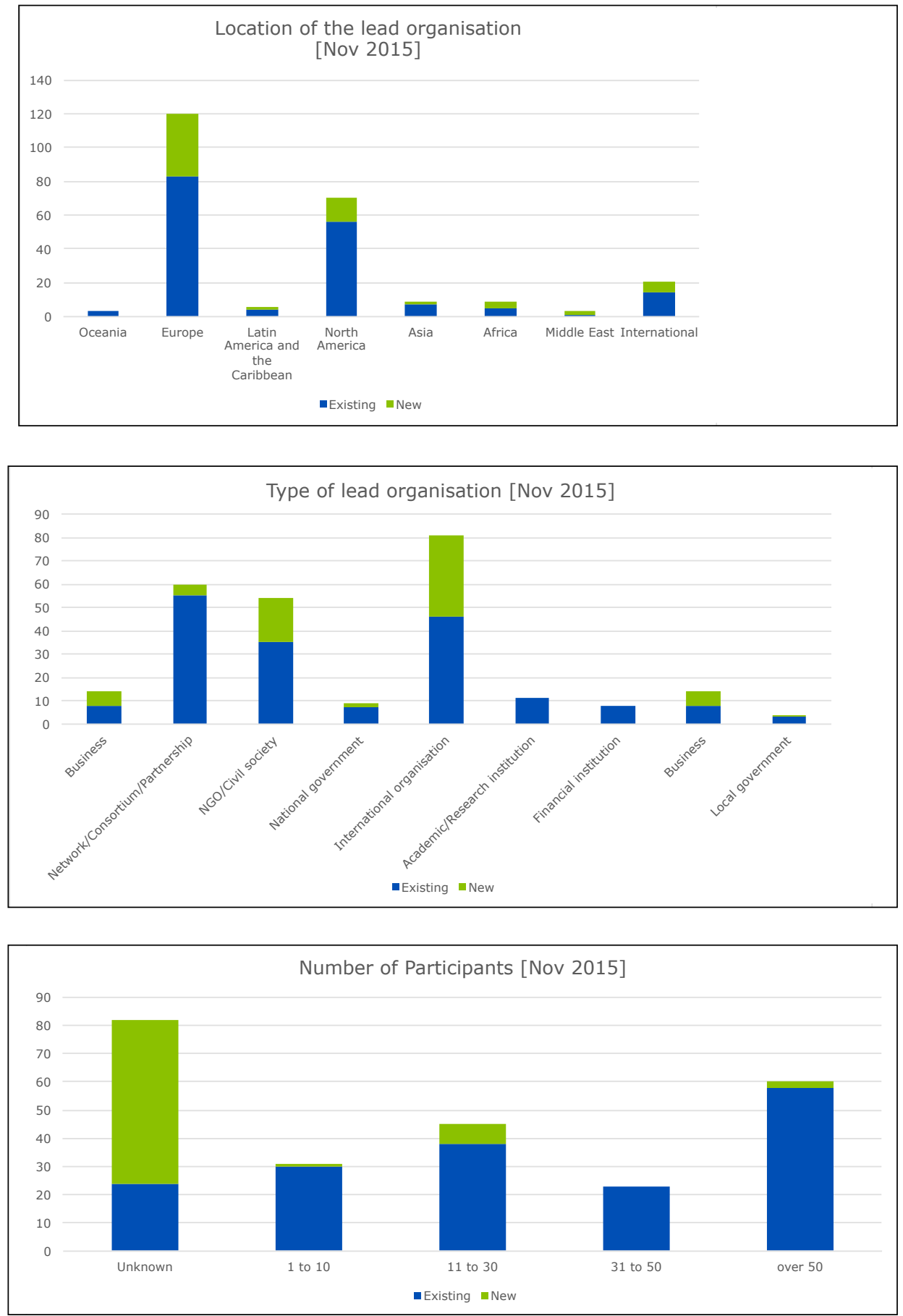

Figure 2

Developments in lead organisation type and location and number of participents. 


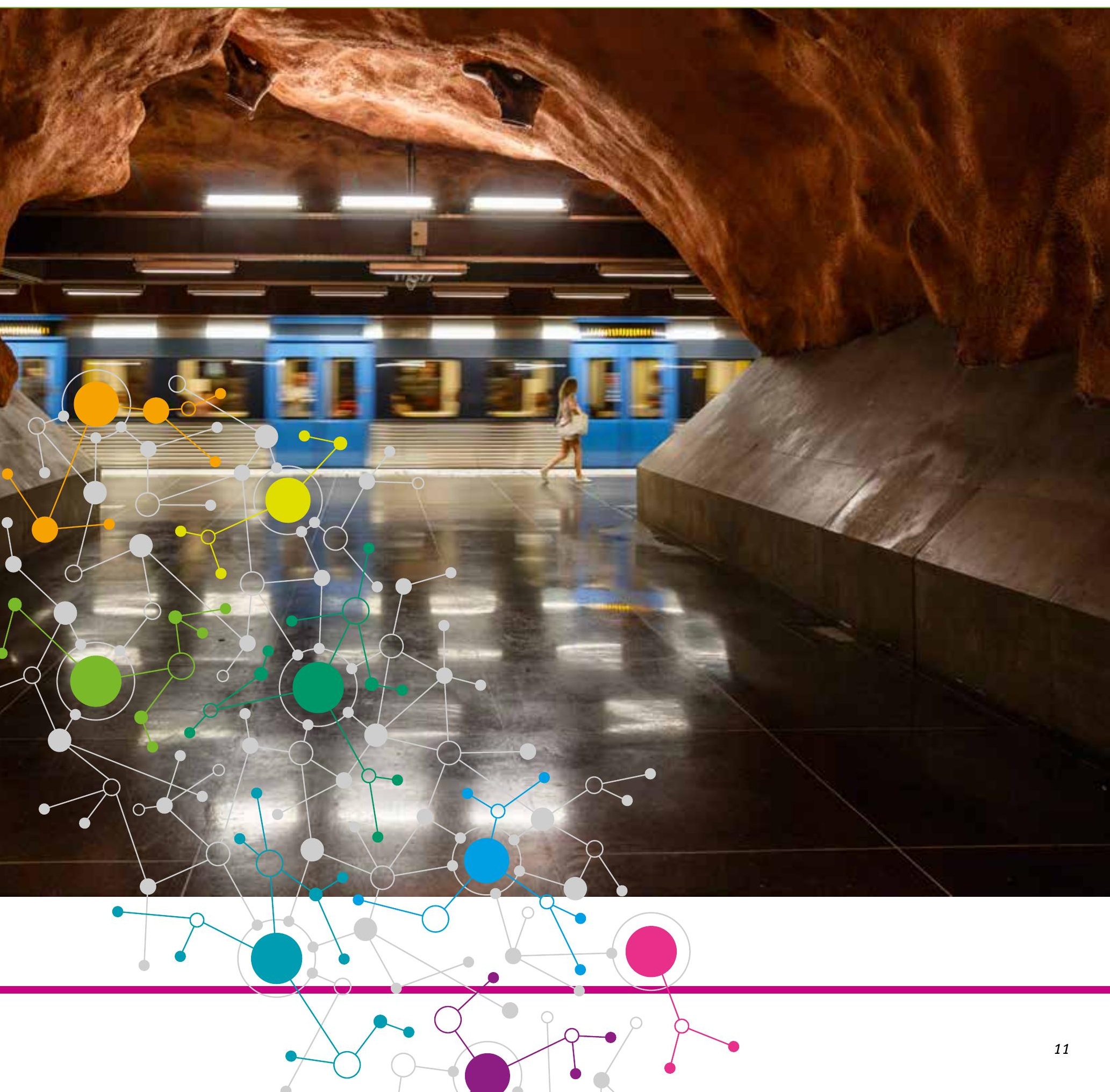




\section{The Climate Initiative Platform and the LPAA}

From the start of the compilation of the Climate Initiative Platform (CIP) the team has been in close cooperation with the UNFCCC. Initiatives identified and listed within the Climate Initiative Platform have also met the criteria and been included in the secretariat's Non-State Actor Zone for Climate Action (NAZCA). This platform was launched during COP20 in Lima in 2014 and registers commitments to climate action by companies, cities, subnational regions, and investors. The NAZCA platform hosts 33 cooperative initiatives that are also registered in the CIP.

To build the momentum to support a universal climate agreement at COP21, the Lima-Paris Action Agenda (LPAA) was formed as a joint undertaking of the Peruvian and French COP presidencies. Since summer of 2015 leading cooperative actions are included on the LPAA website. The LPAA platform showcases transformational initiatives (see text box below), which are accelerating ambition in 2015 and beyond and are compatible to the general goal of not exceeding a $2^{\circ} \mathrm{C}$ temperature increase (science based). Figure 3 and Figure 4 illustrate the scope and overlaps of the different platforms.

The platforms showcase different forms of cooperative initiatives, commitments and ways of collaborating (Figure 3). They further receive their input and information on their listings from different sources (Figure 4).
Figure 3

Breadth of the criteria and focus areas of the three platforms.
Showcases Initiatives that are action oriented and in-line with climate science ( 45 on $11 / 30 / 15$ ).

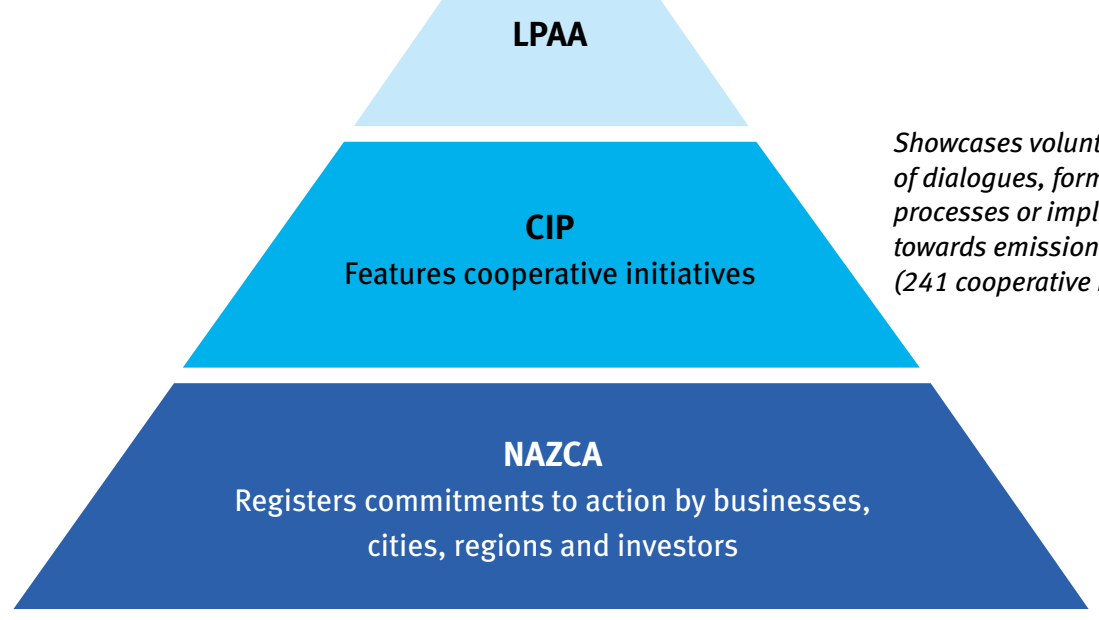

Showcases action at scale that is sufficiently significant to have an impact on mitigation and adaptation. (over 10,800 commitments and growing).

Showcases voluntary action in form towards emission reductions (241 cooperative initiatives). 
Figure 4 further demonstrates the overlap between the different platforms. Although they have slightly different objectives for featuring initiatives, close collaboration and information exchange between them is also illustrated by the fact that 13 of the $45^{2}$ initiatives included in the LPAA were earlier featured on the Climate Initiative Platform.

The Climate Initiative Platform (CIP) hosts extensive information on cooperative initiatives, in which nonstate actors take voluntary action in form of dialogues, formal multilateral process or through implementation. The information available in the platform is mainly open source information enhanced through the input from initiatives themselves.

\section{The Non-State Actor Zone for Climate Action}

(NAZCA) registers commitments to action by businesses, cities, regions and investors. It only hosts a selection of cooperative initiatives that have a clear focus on commitments. Non-state actors are able to register their commitments through the support from extensive global registries like the $\mathrm{CDP}^{3}$ and the Carbonn ${ }^{4}$ registry as well as the global cities and subnational organisation ICLEI. ${ }^{5}$ Both organisations work closely together with the NAZCA portal to provide it with high quality data.

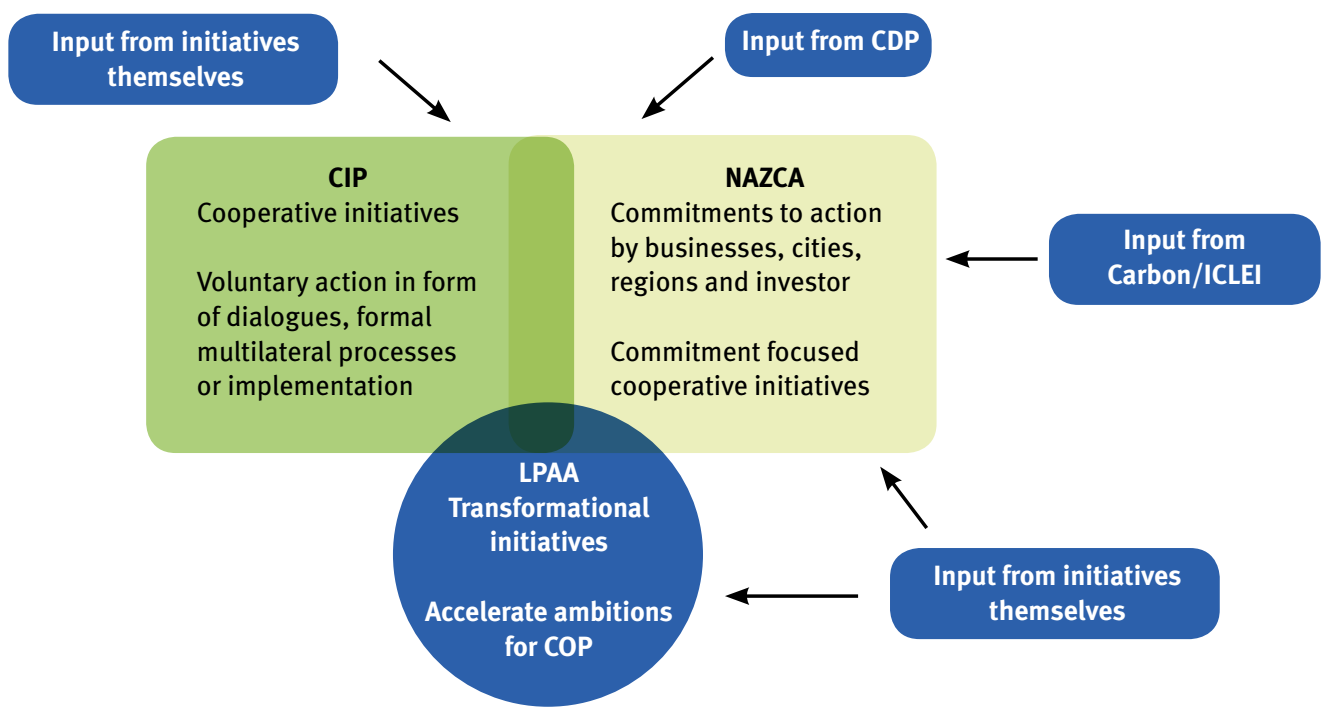

\footnotetext{
${ }^{2}$ As were featured on http://newsroom.unfccc.int/lpaa/ November 30th, 2015.

${ }^{3}$ Formerly known as the Carbon Disclosure Project.

${ }^{4}$ The carbonn $\circledast$ Climate Registry ( $\left.C C R\right)$ is the leading reporting platform to enhance transparency, accountability and credibility of climate action of local and subnational governments.

${ }^{5}$ ICLEI - Local Governments for Sustainability is an international association of local and metropolitan governments dedicated to sustainable development.
} 
The Lima-Paris Action Agenda (LPAA) is the youngest of the platforms and has gathered transformational initiatives with the clear vision to accelerate ambitions for COP21 in Paris. The LPAA received input from initiatives themselves. Box 1 features the LPAA criteria that were applied to select the initiatives that were featured in the run up to Paris.

In this project, we researched other CIP-registered initiatives that could be suitable, based on the above criteria, for further inclusion in the NAZCA and LPAA platforms.

Next to these initial criteria, three further categories Initiative information, Description of initiatives and Expected deliverables and announcements for COP21 were provided by the LPAA ${ }^{6}$ and used by the team to assess the initiatives to put forward for inclusion in LPAA. In general data on the first two categories covering information on the initiatives and its broader description was easily obtained. Information centred around concrete action plans, implementation process and monitoring of activities were often more difficult to find. Few initiatives had information or data on the final category Expected deliverables and announcements for COP21. This included achievements since the 2014 Climate Summit and possible defined baselines to assess these achievements and progress towards Paris.

Applying the LPAA criteria on the available data of CIP-registered initiatives, we identified 18 additional initiatives from the CIP that might be added to LPAA, distributed over different LPAA sectors.

${ }^{6}$ The LPAA developed a template for initiatives interested in joining in which information on the initiative and its plans could be provided by the initiatives.

\section{Box 1}

Criteria for consideration as an LPAA initiative

\section{The LPAA criteria are:}

1. The initiatives' leaders should aim at making them transformative for their sector and ambitious enough to remain on a $2^{\circ} \mathrm{C}$ and resilient pathway, with shortand long-term quantifiable targets.

2. The initiative must be science-based and have a concrete impact on climate change mitigation or adaptation issues within one of the twelve action areas identified.

3. They should be possible to monitor and report on a regular basis.

4. They should also demonstrate the capacity to deliver the commitments made: the leaders must be in the position to implement the proposed solutions on their own.

5. The initiatives' leaders must showcase implementation of existing commitments (sufficient level of maturity in Paris).

6. For cooperative international initiatives: they must observe inclusiveness (e.g. balance regional representation). 
We carried out interviews with 14 of the 18 selected initiatives, to gain a better understanding of the overall setting and development of goals, action plans, future plans and impact assessments.

One specific issue that was raised while discussing the LPAA criteria was how commitments are monitored, a topic that is often not discussed in detail by initiatives. Monitoring practices are not broadly established or are carried out confidentially through a third party. Some initiatives raised practical considerations because of their governance structure regarding aligning targets, future plans and impact assessments with the criteria of the LPAA.

Actions and announcements that CIP-initiatives planned for COP21 were seldom made public. For some initiatives, the UNFCCC process and COP are not of primary concern so they are unlikely to detail current status and future expectations in a way that would have allowed assessment against the LPAA criteria.

The collaborative nature of initiatives makes them particularly sensitive to any calls to reframe or any extra calls on the partners. Initiatives reported that it was always a balance in maintaining focus and momentum with partners and co-collaborators against being responsive and reactive to these extra calls.

\section{The future roles of the platforms}

With the three non-state action platforms now marking their 1st year anniversary it will be interesting to follow the developments they will take individually as well as the ways they will continue to work together. Already now the three platforms are carving out their niches in the increasingly diverse space of non-state climate action.

While NAZCA has grown since December 2014 into an extensive portal that contains over 10,800 commitments and counting over 5,000 actors, ${ }^{7}$ the Climate Initiative Platform remains a source for detailed information on cooperative initiatives, providing insights not only into the actions and commitments taken but also into the way that these commitments are planned to be achieved. The LPAA has been a showcase of the COP presidencies to demonstrate leadership and facilitate and encourage actions beyond the negotiations. The agreement in Paris paves the way for this to continue with a high-level event to be convened in conjunction with the COPs in the period 2016-2020. In addition, two high level champions will be appointed, one from the current and one from the incoming presidencies each year. Regular evaluations of the new commitments and initiatives registered in NAZCA should be made to assess which ones are suitable for inclusion in the Climate Initiative Platform. An increase in initiatives. The number of commitments and initiatives is expected to further grow as parties in Paris have invited non-state actors to register their activities in NAZCA.

${ }^{7}$ As of early 2016 


\section{Findings and outlook from the Update for Paris}

\section{Matching with the UNFCCC process}

There is general interest from the initiatives in giving information that helps others to understand what they do as evidenced by the high willingness to respond, even with short deadlines. However, it was observed that linking directly with the UNFCCC process is not of high interest to many initiatives, as they were formed around different objectives. Linking to the climate negotiations is not what drives them.

Overall a tension exists between the open collaborative nature of cooperative initiatives and the targeted approach of the UNFCCC process, where the accounting for emission reductions to keep in line with the $2^{\circ} \mathrm{C}$ target is the leading criterion for recognition of an initiative. This tension has also been visible within the LPAA.

Nevertheless the level of participation in the Action Day and the focus sessions at Paris suggest that there is a strong groundswell of initiatives who are interested in engaging with the UNFCCC process.

\section{Setting targets}

There are many positive aspects to setting concrete (science-based) targets, like spurring ambition, reducing exposure to policy risks and being visible as a clear leader in one's field. However, target setting is not a priority for many initiatives. As many initiatives are formed around the concept of collaboration, there is often a need for consensus before a concrete target can be set.

A multitude of cooperative initiatives focus on collaboration, knowledge sharing and inclusiveness, looking to expand their activities to a larger number of members or other countries. While creating more impact, these efforts are not always directly translatable into emission reductions. Often there is more flexibility or even encouragement for members to set their own ambitious targets. However, this has the effect that the impact of these initiatives is difficult to quantify. On the other hand, there are some initiatives that set clear targets in line with climate science.

\section{Building trust}

The process of convening and facilitating groups of actors to build independent initiatives is a sensitive and fragile environment. Actors are encouraged to collaborate by interacting with "honest broker" conveners who are able to build trust between different partners and help to construct a valid case for collaborative action. This lays the basis for the ongoing relationships and the potential for impact. It was clear that slight disturbances to this group trust are difficult unless they are felt to be wholly in the group's interest and understood.

\section{Key tool}

The Climate Initiative Platform starts to become a key tool in comparing, contrasting and identifying best 
practice. New initiatives should be supported by further maintenance and investment for the database along with further supporting materials and advice.

Nevertheless the impact assessments of non-state climate action that have been published throughout 2015 clearly demonstrate the significant potential that lies within climate initiatives. Earlier this year an assessment commissioned by (UNEP 2015) estimates that committed action from existing non-state climate initiatives could deliver emission savings of $2.9 \mathrm{GtCO}_{2}$ e by 2020 , which would be additional to what will be delivered by currently implemented policies and measures. A study published by (PBL 2015) in the beginning of November 2015, that looks beyond 2020 commitments observes an increase in the inclusion of sector and city action in the plans put forward by governments in the climate negotiations, resulting in more overlap between climate initiatives and government action. Still the authors see a large potential existing for additional emission reductions from initiatives touching on themes that are currently not included in national pledges. This includes initiatives centred on international shipping and aviation as well as methane and HFC gases.

\section{Providing the evidence}

Overall, during the short course of the project we have seen great enthusiasm from initiatives to contribute to the process and also to help ensure information is up to date in the Climate Initiative Platform. In the weeks leading up to the climate conference in Paris many had been actively working on the presentation of their activities. It will however, be important to keep the momentum for initiatives, whether they are engaged with the LPAA or not well beyond 2015.

Enthusiasm is not the only thing that will need to be maintained. Strengthening the evidence of delivery upon commitments and pledges remains important. The Climate Initiative Platform, specifically designed for this line of evaluations, will be a valuable resource for doing this. To ensure that it will be able to deliver on this vision the transfer of the database will be an important step to making the platform not a stagnate collection of data but a living source of information that is fed through the collaboration between the initiatives and UNEP to ensure continuing quality. 


\section{Transfer of the platform to UNEP - Overall vision}

In this section, we define the overall vision for the Climate Initiative Platform and in the Annexes give more details on how to realise this vision. To facilitate its wider use, the platform will be transferred to the United Nations Environment Programme (UNEP) to form part of their suite of environmental information. The views in this paper are based on our experience with the platform and discussions with an Expert Advisory Group.

The Climate Initiative Platform is intended as an open source of data for use by researchers, policy makers, stakeholders looking for initiatives to join and by the initiatives themselves. As the only source of comprehensive information on cooperative initiatives, it offers the opportunity to be a tool that supports cooperative initiatives in maintaining visibility and increasing their ambition and reach.

\section{Strengthening the Action Agenda}

As discussed above, with the adopted Paris Agreement there is a need to strengthen action on climate, both through state and non-state initiatives. As well as providing the evaluations discussed, the Climate
Initiatives Platform could have a role in strengthening delivery from non-state initiatives. The CIP is a resource that may help to identify initiatives that could improve through support as well as pinpoint what support is needed. As a result of this identification, other parties may make a relatively small investment enabling support, learning and/or advice which could result in a large step forward for the initiative and its activities.

In addition to its open nature, the key recommendations for the platform that we believe are important to maintain or develop further are:

- Inclusive definition of the initiatives that are reported, to allow a broader reflection of activities.

- Flexibility for users to perform their own analysis.

- An expert advisory group to advise and support development.

- Focus on improving the platform to be used to evaluate implementation of the initiatives in more detail.

- Clear and timely communication. 


\section{Inclusive definition of the initiatives}

In Figure 3 we have illustrated the different definitions used by NAZCA, CIP and the LPAA initiatives to select the initiatives hosted on the platforms. The CIP sits in the middle of the three, with a more inclusive definition than the LPAA initiatives, with a clear focus on cooperation that goes beyond commitments. A key aspect for the initiatives featured in the CIP is that they are motivated by two or more parties that come together to take voluntary action towards tackling emission reductions. We see it as important that the definition for initiatives to be featured in the CIP remains inclusive, listing different types of initiatives and their form of interaction, be it through dialogues, formal multilateral processes or clearly geared towards implementation.

\section{Flexibility for users}

The platform has some search functionality implemented but it is relatively limited. The Expert Advisory Group for the development project recommended some improvements to the functionality of the platform. This included more advanced search functions, and a dashboard type interface that allows for greater user interaction and sharing. Based on our experience and literature over the last year, we would suggest dashboards representing at least geographic and sector coverage, initiative and target type, type of lead organisation and size of the initiative reflected in the number of participants or the market share they hold. In addition, as discussed in Annex 4, some fields are included in the database to form the basis for the platform but are not shown publicly on the platform. These mainly cover in-depth information on the target, the overall mitigation potential within the sector or theme. It is recommended that registered researchers be given access to a downloadable version of the database, with suitable provisions on the use of the data and reference to it and also a requirement to make any updates available on the platform.

\section{Expert Advisory Group}

To advise and support the development of the platform, the project convened a group of international experts with a balanced representation from stakeholder groups and technical specialists from research and academic communities (see Annex 2). This advisory group was 
convened to provide a wider view on the potential uses for the platform and its consequent development.

We recommend that there is a continuing role for an Advisory Group as an active part of the enhancement of the platform. We suggest that this Advisory Group is constituted in a similar, but not necessarily identical, manner to the original one to provide a balanced view of the developments necessary in the platform to maintain its leading role.

\section{Focus on evaluation}

With the Paris Agreement it is clear that the world needs to strengthen and increase the speed of implementation and the Climate Initiatives Platform could be a useful tool to evaluate initiatives. This is both in terms of quantitative delivery of mitigation and of the success factors in the way the initiative operates. This can then be applied to other initiatives. However, to do so more, and better verified, data will be needed. More details of this type of data can be found in the report Tracking International Cooperative Initiatives. Annex 4 summarises the data needs for the assessment discussed in this report and also indicates whether the data is already included in the platform.

\section{Clear and timely Communication}

For the CIP to be a widely used tool for initiatives to communicate their activities to a wider audience and for interested actors to use it as a source to gather current information on cooperative initiatives, clear and timely communication is key. This will mean regular updating of the data contained in the CIP with the support of the initiatives themselves. During the process of the update in the fall of 2015 several initiatives have indicated, that they are interested in a way to communicate their activities to the international community. Incentives could be created to make the process of updating information more attractive for initiatives, which could include regular and prominent updates of the website in lead up to future COPs, news articles or links to reports and activities around cooperative initiatives that are relevant for initiatives themselves as well as for the wider community of interested actors.

Annex 1 to this report provides further recommendations and suggestions for putting the here described visions into operation. 


\section{References}

CISL and Ecofys 2015. Better Partnerships:

Understanding and increasing the impact of private sector cooperative initiatives, Cambridge, United Kingdom.

Ecofys and CISL 2014. Enhancing Ambition through International Cooperative Initiatives. Cologne, Germany.

PBL 2015. Climate Action Outside the UNFCCC:

Assessment of the impact of international cooperative initiatives on greenhouse gas emissions. PBL Netherlands Environmental Assessment Agency. The Hague, The Netherlands.

UNEP 2015. Climate commitments of subnational actors and business: A quantitative assessment of their emission reduction impact. United Nations Environment Programme (UNEP), Nairobi, Kenya.

Yale 2015. Scaling Up: Local to Global Climate Action. R20 Regions of Climate Action. Geneva, Switzerland.

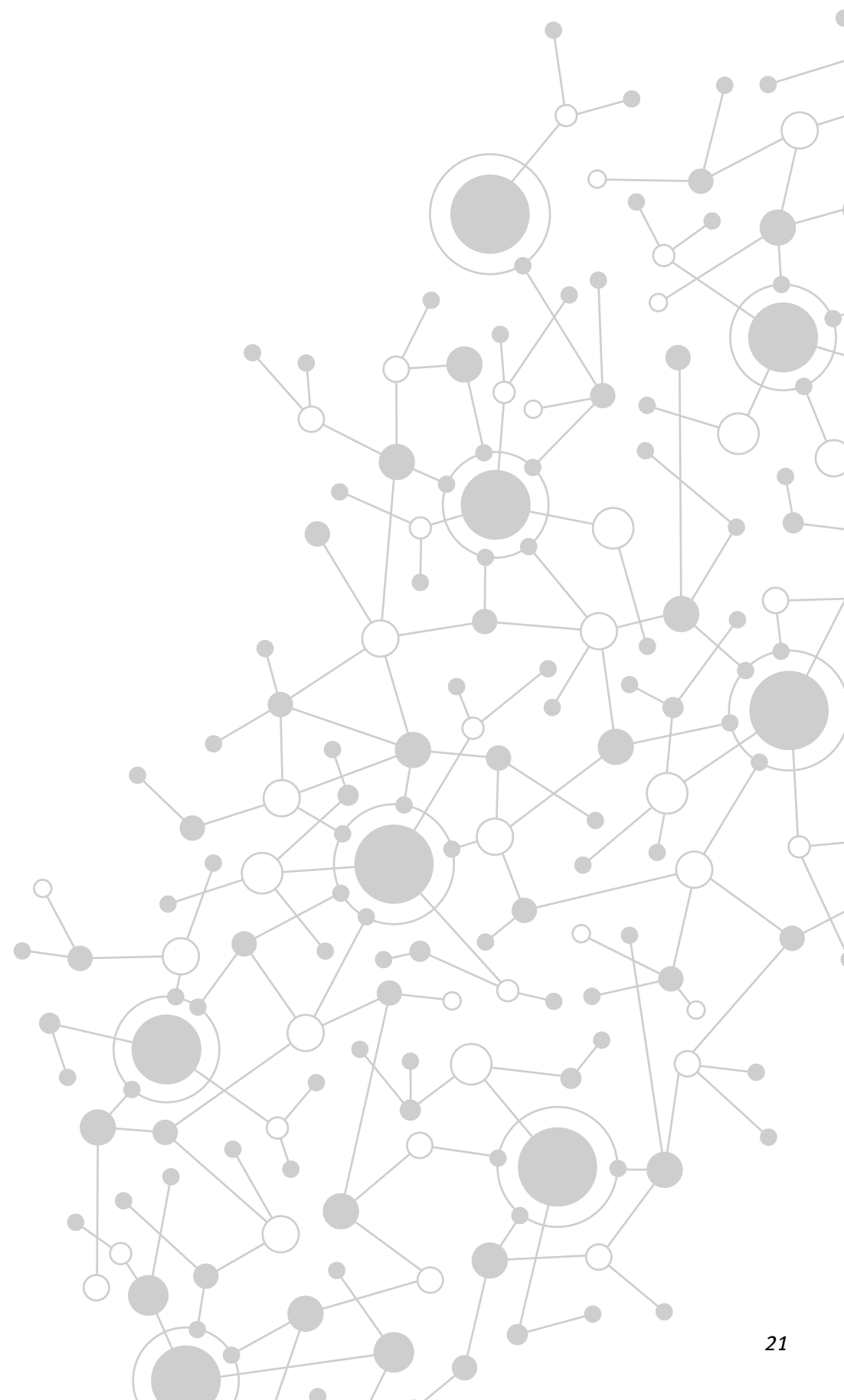




\section{Putting the vision into operation}

\section{Enhancing the data}

The data included in the platform is generally directly quoted and sourced from the initiatives' websites or documents. A direct website link to the initiative is also provided for each entry and users are encouraged to revert directly to the source to retrieve the most accurate and up-to-date information. In October/November 2015, certain initiatives were contacted directly to add some data, but the proportion of initiatives covered in this way is still limited. The platform therefore represents a snapshot of information, the accuracy of which will diminish over time as initiatives' activities evolve.

The Expert Steering Group made some suggestions for improving the data. Based on these suggestions and our own experience, we see a need for more robust, detailed information on the initiatives. The information would be useful for three purposes: to bring cooperative initiatives into the UNFCCC process in a way that could raise ambition; to seed new initiatives and to scale up existing ones.

There are two parts to this, verifying the data already included and adding more data that can be used to assess the contribution from the initiatives as described. Both these can be achieved using the same type of activities:

- Updating data by the initiatives themselves.

- Questionnaires: Surveys could be conducted in the form of questionnaires sent to initiatives included in the climate initiatives platform to collect data that are not publically available.

- Interviews: Interviews in person or by phone can also be conducted to gather data. They are more time intensive but could result in greater quality data, with the opportunity for follow up responses.

To increase efficiency, questionnaires or interviews could be conducted on the side lines of any regular convening of initiatives.

The platform has been implemented in a Wiki format so allowing user input is very practical. In the interviews carried out during October/November 2015 it appears that initiatives were interested in a way to communicate their activities. However, there would need to be an incentive for them to do so. For example, regular updates 
of the website would be needed to showcase initiatives or provide news articles based on the platform to encourage initiatives to keep information up to date. Similarly there could be links to other reports and activities that are relevant for initiatives.

To ensure that there are no issues of data incompatibility it is recommended that a form is provided to input data, which is then checked by the platform managers before adding to the live platform. This also allows the platform manager to contact the initiatives to clarify any of the information. The time-scales for this checking needs to be agreed and clearly communicated as there will need to be a balance between resource availability and ensuring that the initiatives do not see a lack of response to their input. Perhaps opening a window of time for input, accompanied by appropriate publicity, would be a suitable way forward if full time responsiveness is not available.

It is likely that updating by the initiatives themselves will only be successful for a limited number. To keep the CIP relevant it is recommended that the remainder of the information is checked and updated at least yearly.

\section{Communication}

There are two aspects of communication that will be important, one ensuring that the platform is known and used by practitioners and initiatives and two communicating results of analysis based on the platform.

To ensure the platform is known the following can be carried out:

- Recruitment of new users by increasing the profile of the platform and a proactive outreach campaign.

- Online promotion - including for example: ensuring domain well linked through all major online platforms, platforms etc.; Placement of promotional editorials, articles etc.; Promotion through social media (LinkedIn, Twitter, Facebook etc.).

- Presentations at key events/meetings - Showcasing platform at key meetings of target users and stakeholders (e.g. UNFCCC/UN, funders/Donors, Policy/Researchers).

As discussed previously, results of the assessment of initiatives will be needed to understand both their aggregate effect and the areas ripe for seeding or 
strengthening. The way these aspects need to be communicated will be different and will depend on the audience. It is therefore recommended that a mixture of communication be used, including regular reports (for example, see the NAMA Status Reports and UNEP Emissions Gap Reports) and tailor made reports on the effect of individual initiatives or of groups of initiatives (e.g. in a certain sector, addressing a certain problem, demonstrating the co-benefits). The regular report is recommended because experience has been that the annual (or biannual) reports can keep the topic centre stage. Reports however reach only a part of the audience that would be interested in the results of these initiatives. Other ways of engagement would also be needed for example videos, round tables, public-private dialogues and many others.

\section{Outline work programme}

The following is a suggested outline work programme for hosting the database. Transfer of the database to the UNEP host is discussed in Annex 3.

\section{Advisory Group}

- Identify and invite potential members.

- Manage periodic consultation.

- Recruit/replace new members as needed.

\section{Functioning of the website}

- Develop and implement input form and procedure for moderating input.

- Prioritise improvements to the functioning of the website (with Advisory Group) and implement.

- Provide maintenance of the website as outlined in Annex 3.

\section{Improvement of the data}

- Identify which additional data fields need to be added to improve the assessment made possible using the database. This can be based on Annex 4 and advice from the Advisory Group.

- Populate data fields from desk based research.

- Complete verification of the data in the platform by contact with initiatives (where not already done in 2015).

- Review and update data periodically.

\section{Communication}

- Promotional campaign based on the transfer of the platform to UNEP.

- Two to three publications based on the platform throughout the year - presented at appropriate venues.

- Annual report based on the platform updating progress on initiatives and setting in the context of international action on climate change. 


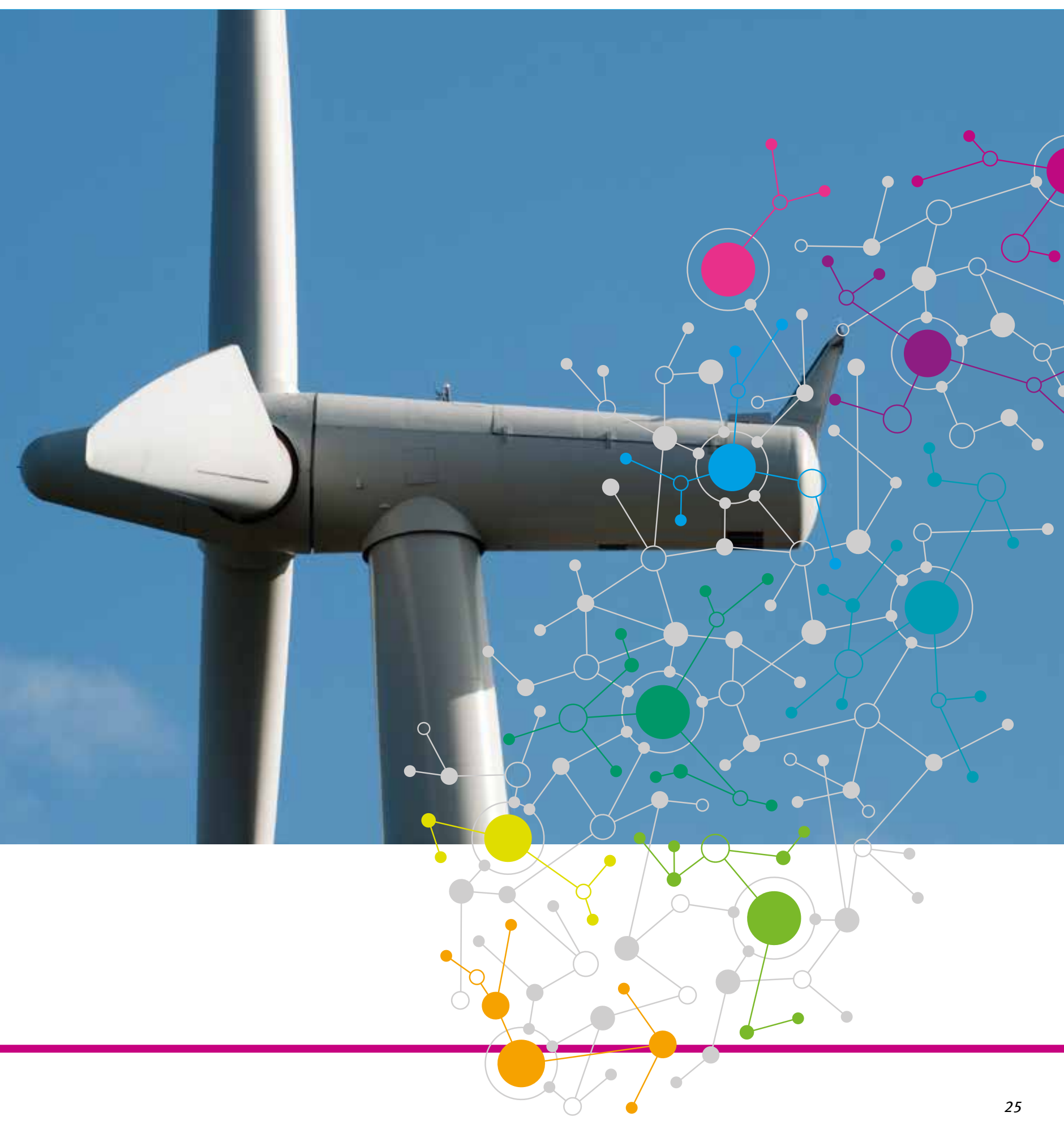


Annex 2

\title{
Expert Advisory Group
}

The Expert Advisory Group for the platform development included:

\author{
/ Laura Aho (Government of Finland) \\ / Marcel Berk (Government of the Netherlands) \\ / Lara Birkes (WBCSD) \\ / Sander Chan (DIE) \\ / Philip Drost (UNEP) \\ / Todd Edwards (Stanley Foundation) \\ / Ipek Gencsu (New Climate Economy) \\ / Andrew Higham (UNFCCC) \\ / Thomas Hale (Oxford University) \\ / Line Skou Hauschildt (Government of Denmark) \\ / Niklas Höhne (NewClimate Institute) \\ / Michael Jacobs (New Climate Economy) \\ / Outi Leskelä (Nordic Council of Ministers) \\ / Christoffer Nelson (Government of Sweden) \\ / Ian Ponce (UNFCCC) \\ / Alejandro Rivera (Government of Mexico) \\ / Stef Raubenheimer (SouthSouthNorth) \\ / Cynthia Scharf (UN SG) \\ / Seth Shultz (C40) \\ / Håvard Toresen (Government of Norway) \\ / Maria Vuorelma (Government of Finland) \\ / Paul Watkinson (Government of France) \\ / Harald Winkler (University of Cape Town) \\ / Lutz Weischer (Germanwatch) \\ / Farhana Yamin (Track0)
}




\section{Transfer of the platform to UNEP and maintenance}

To carry out the transfer a backup will need to be made of the MySQL platform and all (PHP) file systems will be zipped. Via FTP the files will be transported to the new hosting environment. The IP number associated with the domain will be changed to the IP number of the new server. The challenge will be to realise these steps with minimum of down time.

\section{Maintenance and support of the platform}

The recommended activities are needed to ensure that the platform remains a useful, and known, resource to researchers and comprise of:

- General domain management covering for example: maintaining the domain name; keeping wiki software updated; resolving any domain issues arising; optimising for web searches.
- Minor improvements to the platform and website including giving more clarity on what initiatives are included and improving definitions of the information fields.

- User support activities including for example: answering general user enquiries; supporting new logins; changing login privileges; creating bespoke logins (e.g. with tailored access to specific areas); blocking unwanted users.

- Supporting users to get the best from the platform by e.g. creating bespoke enquiry forms/dashboard interfaces and search functions; helping users link to the data or use for their own purposes; carrying out user survey/evaluations. 
Annex 4

\section{Data for assessment}

\begin{tabular}{|c|c|c|c|}
\hline $\begin{array}{l}\text { Criterion } \\
\text { Governance (leadership, goals, } \\
\text { participation) }\end{array}$ & $\begin{array}{l}\text { Can data be collected? } \\
\text { With what ease? }\end{array}$ & $\begin{array}{l}\text { Can the criterion be assessed } \\
\text { in an objective manner? }\end{array}$ & Already included? \\
\hline Identified lead organization(s) & Yes, likely publically available & Yes & Yes \\
\hline $\begin{array}{l}\text { Number of organizations } \\
\text { participating }\end{array}$ & Yes, likely publically available & Yes & Yes \\
\hline Articulation of Initiative's goal & Yes, likely publically available & Yes & Yes \\
\hline Quantification of Initiative's goal & Yes, likely publically available & Yes & Where available \\
\hline $\begin{array}{l}\text { Existence of milestones for the } \\
\text { achievement of the initiative's } \\
\text { goals (either individual member } \\
\text { or collective) }\end{array}$ & Yes, may be publically available & Yes & No \\
\hline $\begin{array}{l}\text { Design of a goal in response to a } \\
\text { governance gap }\end{array}$ & Yes, may not be publically available & Yes & No \\
\hline $\begin{array}{l}\text { Design of a goal to assist in } \\
\text { the implementation of existing } \\
\text { goals or policies (e.g. national } \\
\text { government, UNFCCC, etc.) }\end{array}$ & Yes, may not be publically available & Yes & Where specified \\
\hline $\begin{array}{l}\text { Existence of penalties for } \\
\text { participants not meeting } \\
\text { membership requirements }\end{array}$ & Yes, likely not publically available & Yes & No \\
\hline $\begin{array}{l}\text { Distribution of decision-making } \\
\text { power }\end{array}$ & Yes, likely not publically available & $\begin{array}{l}\text { Yes, insofar as distributed } \\
\text { decision-making power } \\
\text { is defined further (e.g. } \\
\text { governed by a board } \\
\text { comprised of multiple types } \\
\text { of stakeholders, who hold } \\
\text { equal weight in decision } \\
\text { making) }\end{array}$ & No \\
\hline $\begin{array}{l}\text { Existence of a regular review of } \\
\text { the goal }\end{array}$ & Yes, likely not publically available & $\begin{array}{l}\text { Yes, would have to determine } \\
\text { what constitutes "regular", } \\
\text { e.g. annually }\end{array}$ & No \\
\hline Process for establishing the goal & Likely not publically available & $\begin{array}{l}\text { Not easily in current } \\
\text { formulation }\end{array}$ & No \\
\hline $\begin{array}{l}\text { Collaboration with other } \\
\text { initiatives }\end{array}$ & Likely not publically available & $\begin{array}{l}\text { Not easily in current } \\
\text { formulation. Difficult to } \\
\text { define "collaboration" }\end{array}$ & No \\
\hline
\end{tabular}




\begin{tabular}{|c|c|c|c|}
\hline $\begin{array}{l}\text { Criterion } \\
\text { Transparency and Accountability }\end{array}$ & $\begin{array}{l}\text { Can data be collected? } \\
\text { With what ease? }\end{array}$ & $\begin{array}{l}\text { Can the criterion be assessed } \\
\text { in an objective manner? }\end{array}$ & Already included? \\
\hline Publically available reporting & Yes & Yes & $\begin{array}{l}\text { Yes (but only } \\
\text { indicates whether it } \\
\text { is reported or not) }\end{array}$ \\
\hline Third party verified reporting & Yes & Yes & No \\
\hline $\begin{array}{l}\text { Existence of regular reporting of } \\
\text { progress }\end{array}$ & Yes, may not be publically available & Yes & No \\
\hline $\begin{array}{l}\text { Reporting of progress against } \\
\text { the goal }\end{array}$ & Yes, may not be publically available & Yes & No \\
\hline $\begin{array}{l}\text { Results of any quantification of } \\
\text { reporting of progress }\end{array}$ & Yes, may not be publically available & $\begin{array}{l}\text { Yes, can assess availability } \\
\text { of quantified progress, but } \\
\text { comparability will be limited } \\
\text { if common methods for } \\
\text { quantification are not used }\end{array}$ & $\begin{array}{l}\text { Some } \\
\text { quantification } \\
\text { based on 3rd } \\
\text { party reports } \\
\text { not reporting by } \\
\text { initiatives }\end{array}$ \\
\hline \multicolumn{4}{|l|}{ Resources } \\
\hline Available resources & $\begin{array}{l}\text { Yes, not publically available but has } \\
\text { been provided to LPAA }\end{array}$ & Yes & No \\
\hline $\begin{array}{l}\text { Quantity of full time staff } \\
\text { working on coordinating the } \\
\text { initiative }\end{array}$ & $\begin{array}{l}\text { Yes, not publically available but has } \\
\text { been provided to LPAA }\end{array}$ & Yes & No \\
\hline $\begin{array}{l}\text { Quantity of designated staff } \\
\text { working to coordinate the } \\
\text { initiative }\end{array}$ & $\begin{array}{l}\text { Yes, not publically available but has } \\
\text { been provided to LPAA }\end{array}$ & Yes & No \\
\hline Fundraising goals established & $\begin{array}{l}\text { Yes, not publically available but has } \\
\text { been provided to LPAA }\end{array}$ & Yes & No \\
\hline $\begin{array}{l}\text { Projected future costs given } \\
\text { objective of the initiative }\end{array}$ & Yes, likely not publically available & $\begin{array}{l}\text { Yes, can assess availability } \\
\text { of cost estimate, but } \\
\text { comparability will be limited } \\
\text { if common methods for } \\
\text { estimation are not used }\end{array}$ & No \\
\hline Estimated costs & Yes, likely not publically available & $\begin{array}{l}\text { Yes, can assess availability } \\
\text { of cost estimate, but } \\
\text { comparability will be limited } \\
\text { if common methods for } \\
\text { estimation are not used }\end{array}$ & No \\
\hline
\end{tabular}




\begin{tabular}{|c|c|c|c|}
\hline $\begin{array}{l}\text { Criterion } \\
\text { Impact }\end{array}$ & $\begin{array}{l}\text { Can data be collected? } \\
\text { With what ease? }\end{array}$ & $\begin{array}{l}\text { Can the criterion be assessed } \\
\text { in an objective manner? }\end{array}$ & Already included? \\
\hline Assumed beneficiaries & Yes, may be publically available & Yes & No \\
\hline $\begin{array}{l}\text { Identification of clear benefits } \\
\text { for participating }\end{array}$ & Yes, may be publically available & $\begin{array}{l}\text { Yes, can assess whether } \\
\text { there is a statement on } \\
\text { benefits to participants }\end{array}$ & $\begin{array}{l}\text { For some is in } \\
\text { description }\end{array}$ \\
\hline $\begin{array}{l}\text { Assumed benefits/effects } \\
\text { (If quantified state what the } \\
\text { effect is) }\end{array}$ & Yes, may be publically available & $\begin{array}{l}\text { Yes, can assess availability } \\
\text { of information on assumed } \\
\text { benefits of the initiative, } \\
\text { but comparability limited } \\
\text { if common methods for } \\
\text { assessing benefits are } \\
\text { not used }\end{array}$ & No \\
\hline $\begin{array}{l}\text { Assumed co-benefits } \\
\text { (If quantified what the effect is) }\end{array}$ & Yes, may be publically available & $\begin{array}{l}\text { Yes, can assess availability of } \\
\text { information on assumed co- } \\
\text { benefits, but comparability } \\
\text { limited if common methods } \\
\text { for assessing benefits are } \\
\text { not used }\end{array}$ & No \\
\hline $\begin{array}{l}\text { Exclusive of benefits to } \\
\text { participants. If not to whom? }\end{array}$ & Yes, may not be publically available & Yes & No \\
\hline $\begin{array}{l}\text { Equal availability of benefits to } \\
\text { all participants }\end{array}$ & Yes, may not be publically available & $\begin{array}{l}\text { Yes, can assess whether } \\
\text { all participants have equal } \\
\text { access to stated benefits }\end{array}$ & No \\
\hline $\begin{array}{l}\text { Identification of potential risks } \\
\text { identified; If so, which ones? }\end{array}$ & Yes, likely not publically available & $\begin{array}{l}\text { Yes, can assess whether risks } \\
\text { have been identified, but } \\
\text { will be necessary to define } \\
\text { "risks" so data are collected } \\
\text { in a similar fashion across } \\
\text { initiatives }\end{array}$ & No \\
\hline
\end{tabular}




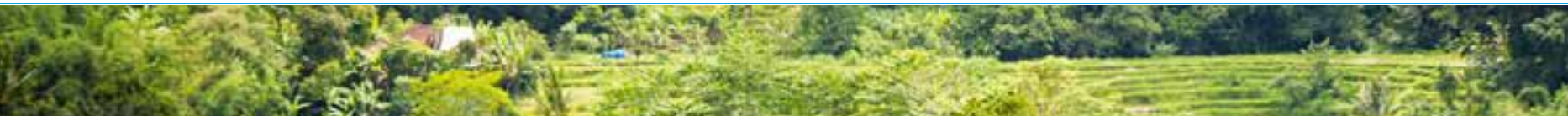

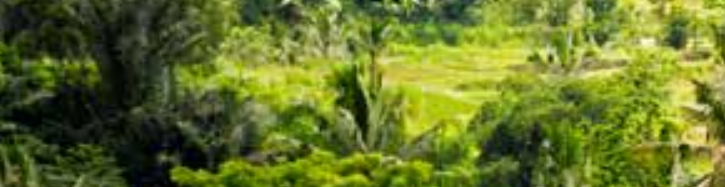

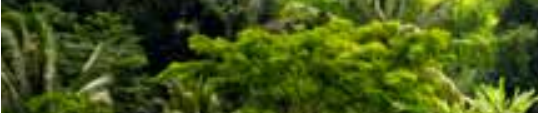
130
3

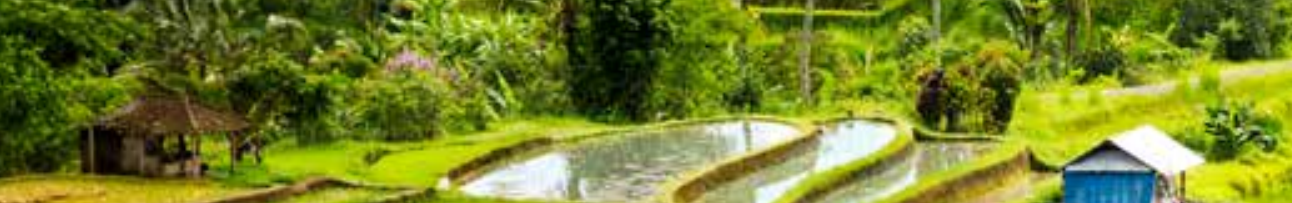

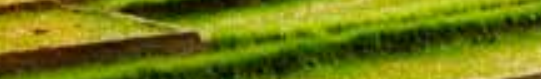

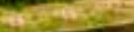
. ( Pint

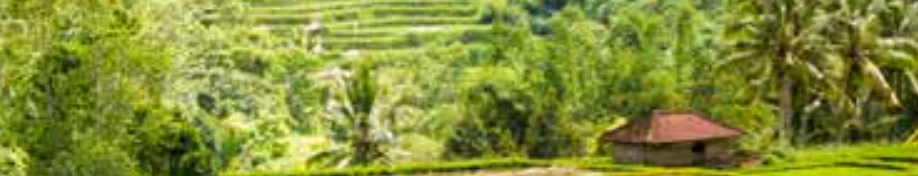

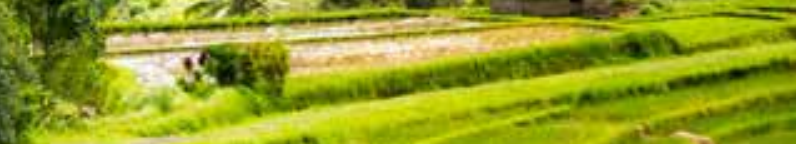

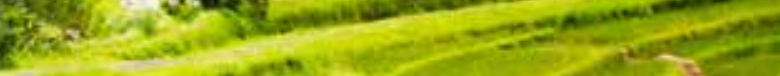
(2.:-

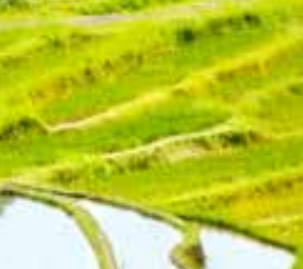

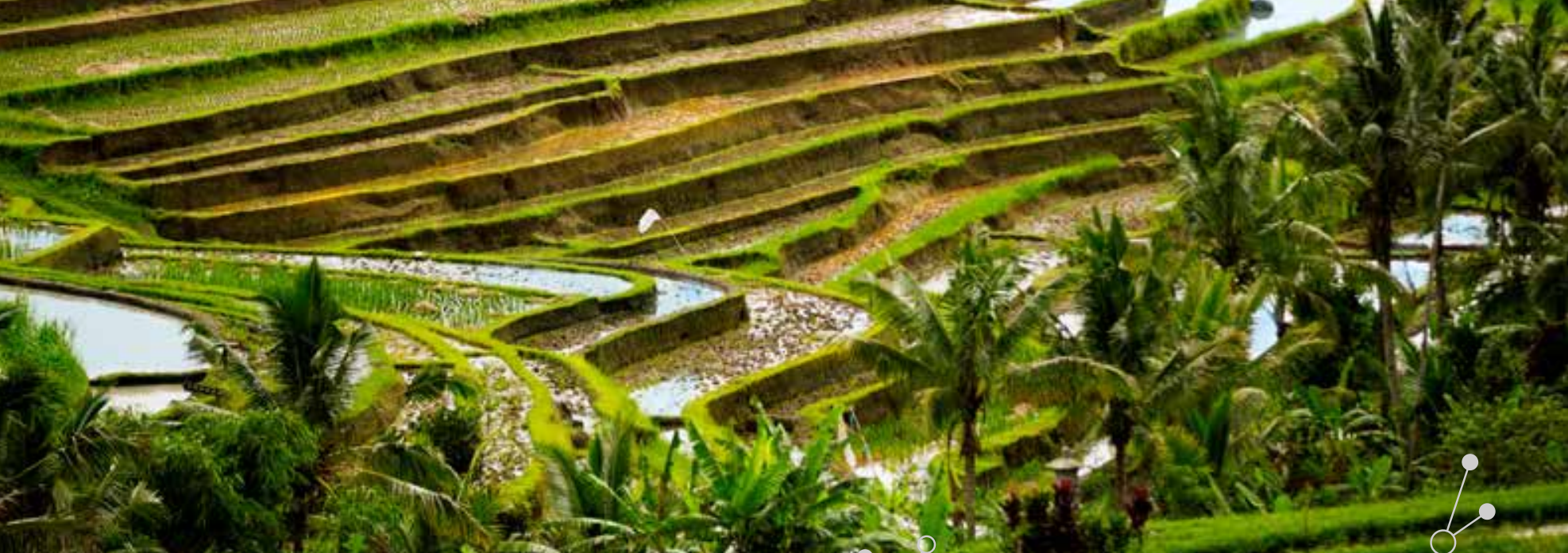

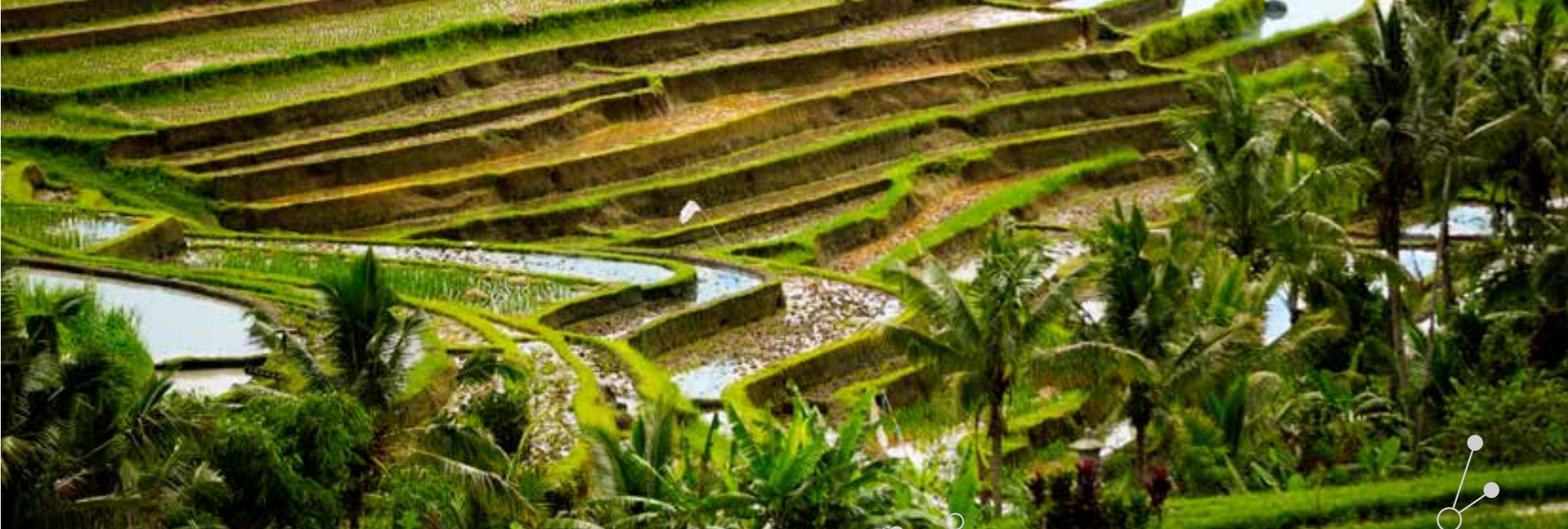

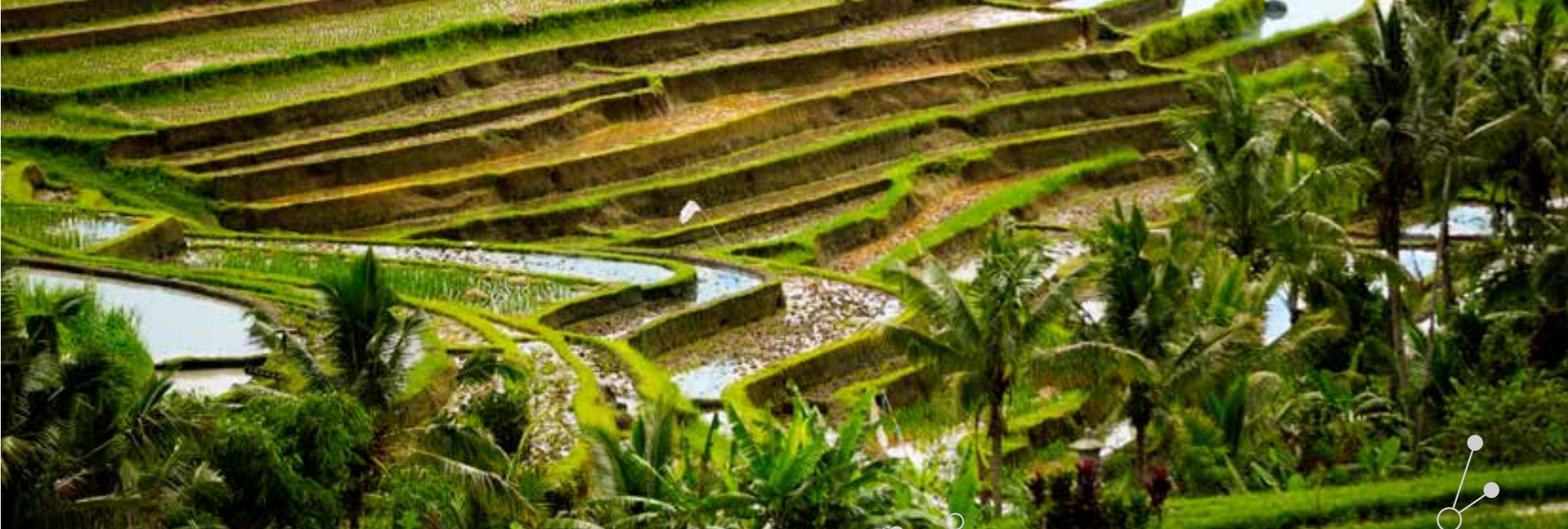

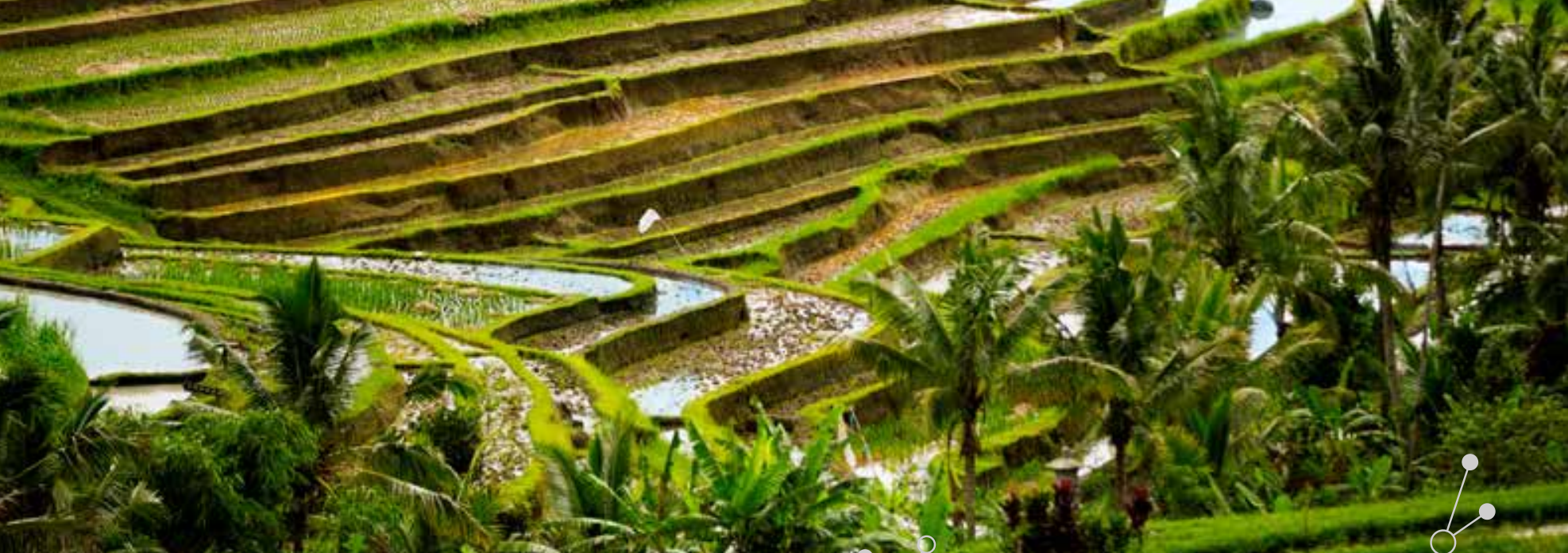




\section{กั}

Nordic Council of Ministers

Ved Stranden 18

DK-1061 Copenhagen K

www.norden.org

ANP 2016:716

ISBN 978-92-893-4517-0 (PRINT)

ISBN 978-92-893-4518-7 (PDF)

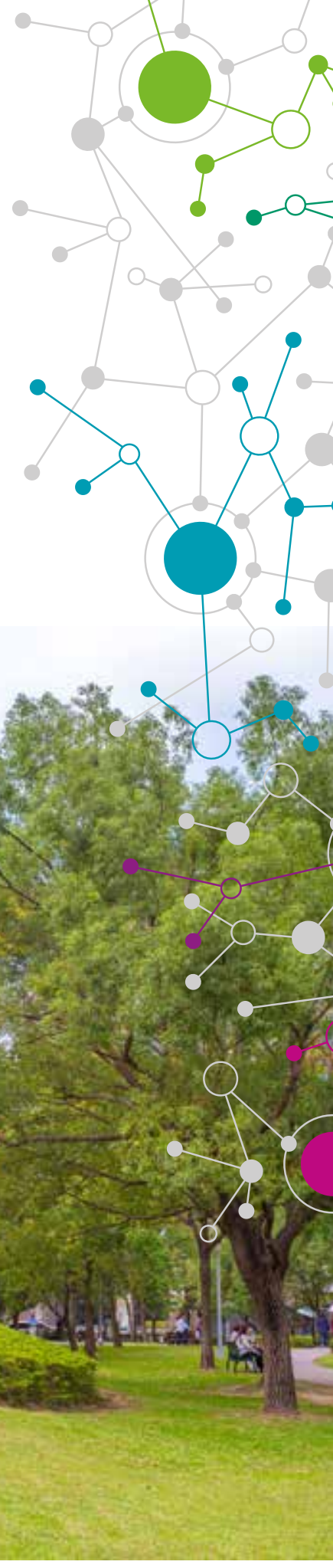

